\title{
Educational Game Model for Pre-School CHILDREN
}

\author{
Karuovic, D.; RAdOSAV, D. \& GlusaC, D.
}

Abstract: In this paper, in empirical research the tendency of the development and implementation of new models of teaching and learning with the participation of modern information technology and above all, human computer interaction (HCI) has been presented. The models and forms of interaction at creating user interface educational software for pre-school children will be presented as well. Overview and possible classification of educational games are presented, too. This paper includes the examples of educational games developed at University of Novi Sad, Technical Faculty "Mihajlo Pupin" in Zrenjanin, under the thesis "User Interface Model of Interactive Educational Software".

Key words: HCI, educational software, educational game, children
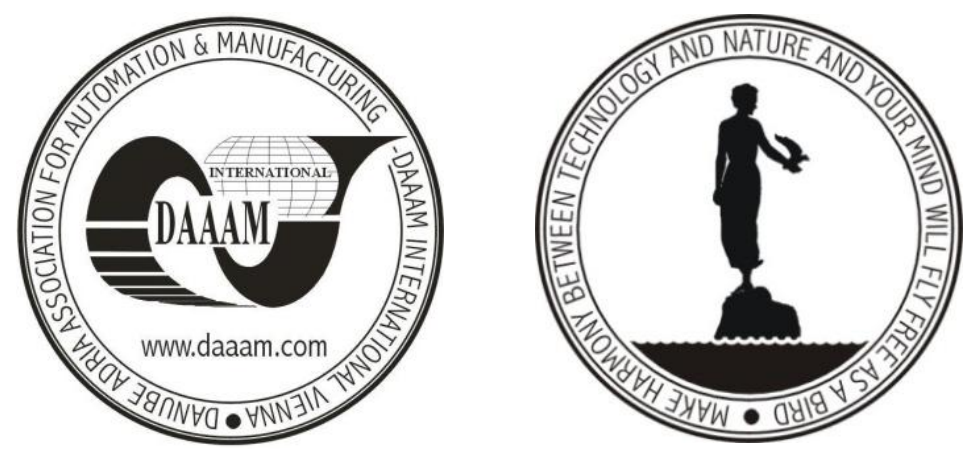

Authors' data: Dr.Sc. Karuovic, D[ijana]; Univ. Prof. Dr. Sc. Radosav, D[ragica], Univ. Prof. Dr. Sc. Glusac, D[ragana], University of Novi Sad, Technical Faculty "Mihajlo Pupin“, Djure Djakovica BB, Zrenjanin, Serbia, aruena@tfzr.uns.ac.rs, radosav@tfzr.uns.ac.rs,gdragana@tfzr.uns.ac.rs

This Publication has to be referred as: Karuovic, D[ijana]; Radosav, D[ragica] \& Glusac, D[ragana] (2010). Educational Game Model for Pre-School Children, Chapter 12 in DAAAM International Scientific Book 2010, pp. 107-116, B. Katalinic (Ed.), Published by DAAAM International, ISBN 978-3-901509-74-2, ISSN 17269687, Vienna, Austria

DOI: 10.2507/daaam.scibook.2010.12 
Karuovic, D.; Radosav, D. \& Glusac, D.: Educational Game Model for Pre-School ...

\section{Introduction}

Computer games are widely accepted form of entertainment and their popularity has increased over the past three decades. There are a lot of different studies concerning computer games and their influence on cognitive performance. It has been shown that computer games have great potential as a learning tool for the following reasons (Mayo, 2007):

- $\quad$ They can affect much more users than 'normal' lesson

- They can be played anytime, anywhere

- $\quad$ They are designed according to effective learning paradigms

- They stimulate chemical changes in the brain that promote learning

In the same time, games were associated with the concept of fun, while with learning it seemed that it was not always the case (Prensky, 2007). Games used several different techniques that kept the player motivated. Also, it has been noted that play improves ability to reason and understand the world (Gilkey\& Kilts, 2007).

The following elements of flow are manifested in computer games and learning environments: task that can be completed, ability to concentrate on it, task has clear goals and it provides immediate feedback, deep but effortless involvement, exercising a sense of control over actions, concern for self disappears during the flow, but sense of self is stronger after flow activity and sense of duration of time is altered (Marshall, 1998).

\section{Theoretical Approaches of Researching}

\subsection{Problem and subject of research}

When we talk about interactive models, we have to deal with cognitive models, from the standpoint of users, related to knowledge, understanding, intentions and attitudes. The important terms in interaction are: domain - the field of work (example: graphic design), aim (example: creating the red triangle) and task (example: selection of drawing tools). Interactive models should improve usability degree of created systems.

D. Norman's model is concentrated to user's comprehension of interface and it includes the following seven stages:

1. Establishment of the aim,

2. Formulation of purpose,

3. Specification of interfaceaction,

4. Action performance,

5. Observation of system's state,

6. Interpretation of system's state and

7. validity of system's state in relation to the aim. (Radosav\&Marušić, 2007). 
In the following part some cognitive models will be presented:

- CCT (Cognitive Complexity Theory) - techniques are established on the hierarchy of aims and tasks. The basic pre-condition is that a man accepts information from the real world and creates certain images in his brain. This kind of presentation is usually called knowledge. There are two parallel descriptions: user's production of rules and generated networks of transmition aided by certain devices.

- CTA (Cognitive Task Analysis) - asks for a model of internal presentation and it processes it in order to design tasks that a child will fulfill efficiently.

- HTA (Hierachical Task Analysis) - it was originally developed for identification of training needs. It asumes a division of tasks on sub-tasks and again on sub-tasks, etc. Afterwards, the tasks are grouped as plans that indicate the ways for realization of tasks in real situations. HTA is focused at physical activities that are realized. The starting point is user's aim. Then, the aim should be examined and the main tasks by which the identification of the aim is achieved are added.

The first educational video games were developed in order to practice certain activities on computers or in order to improve the teaching process and to drill the tasks. Later, the games including simulations and strategies were developed. Computer games are good for introducing pre-school children in educational system because they contain all the elements which are attractive for children: many colors, animation, sound...

In order to evaluate the attractiveness of online computer games, staying in the game (Ag) is defined similarly to measurment called staying on the page (Ast) which was developed in order to validate the effectiveness of web page. Staying on the page in considered an useful indicator of web user favor in order to react favorably or the opposite to the web content in certain situations (Chen \& Wells, 1999).

Theory of reasoned actions (TRA) has become widely studied model in social psychology which demonstrates a relation between the intentions of staying and behaviour (Ajzen \& Fishbein, 1980; Fishbein \& Ajzen, 1975). According to TRA, behaviour of an individual is determined by his/her intentions of behaviour. An individual's intention to visit web page again or to return to it because of the game can be understood as a result of his/her attitude towards the use of technologies that urge people to reuse them in the future (TAM) (Davis, 1989; Davis et al., 1989). Namely, «Ag» is considered a significant indicator of games' effectiveness concerning attraction of current and potential players.

The intention for revisiting the web page is another indicator of page effectiveness. Since online computer games have been presented and played in web browser surroundings, the intention of a player to return to the game is determined, in great extent, by presentation contents. Visitors' attitudes towards the page 
Karuovic, D.; Radosav, D. \& Glusac, D.: Educational Game Model for Pre-School ... immediately influence their processing of the page contents. They can also influence the visitors' intention to revisit the page (Gao, 2005).

In the figure 1 it is presented a relationship between attitudes to computer game and the intention to revisit the game.

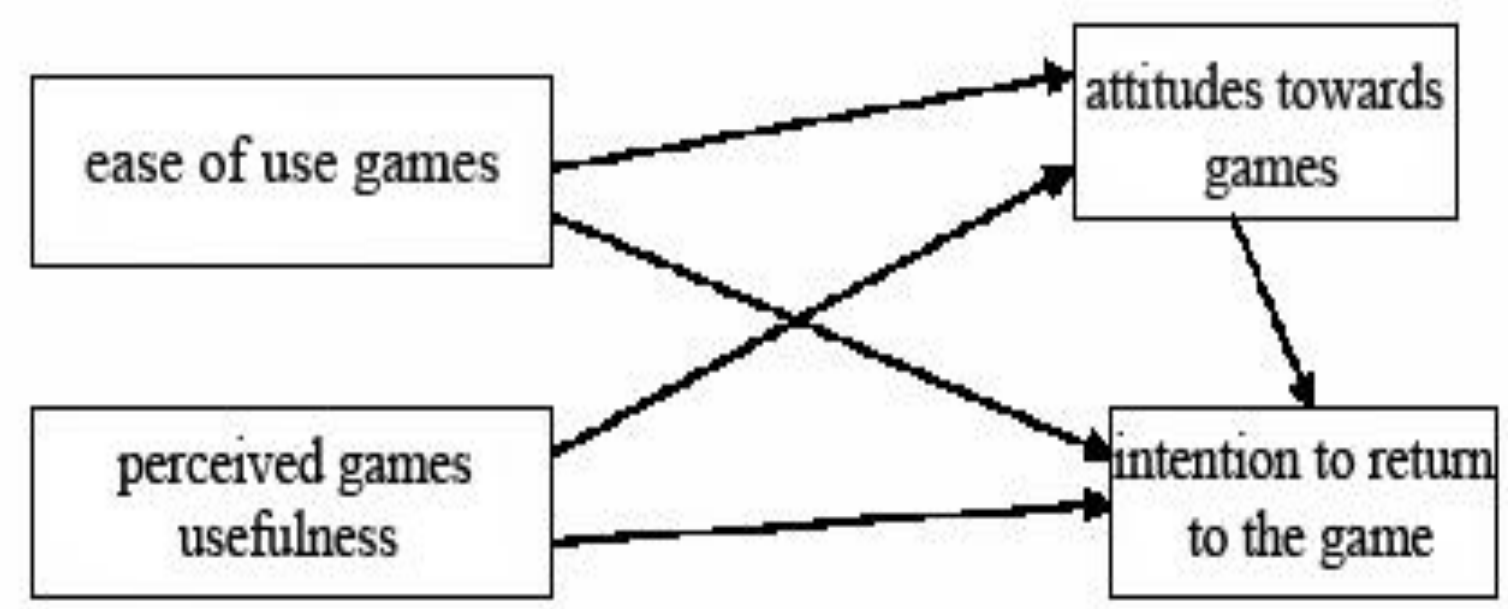

Fig. 1. A Relationship between attitudes to computer game and the intention to revisit the game

The important component of computer games is entertainment. Online effect of entertaining games represent an important source of value for visitors and players. Messages presented in entertainment formats were considered to contribute to more positive attitude (Mitchell\&Olson, 1981).

Colors play a big part in visual design of games because they are added to all elements, including texts. All colors, except grey, generally create certain emotions (Chapman\&Chapman 2006b, 588). In other words, it is impossible to discuss colors without expressing personal taste, aesthetics, cultural differences, fashion, etc. It often happens in practice that even older users are not able to notice different contents because of inappropriate design of educative games. For all these reasons, in the part of the thesis which represents the base of this paper, a special attention is paid to testing color elements on the screen and their adaptation to pre-school children.

When designing a graphical user interface for pre-school children, important is:

- ensure that all data that are required to, be made available on the screen,

- maintain consistency in presentation of data

- use short, clear sentences,

- use gentle, positive tone during the presentation,

- mark each page

- carefully use color (Karuovic, Radosav \& Glusac, 2008.) 


\subsection{The research goals}

The aim of the research is to the discover the unknown facts about the characteristics of user acceptance of information from the standpoint of concepts, discovery of trends in development of user interfaces as part of interactive educational software, discovery of conditions, reasons and motives that lead to the fact that educational games have a significant impact on the quality, efficiency and productivity of the educational process.

\subsection{The research hypothesis}

General hypothesis of the research is: educational games providing greater direct knowledge of users, as well as a higher level of development of cognitive, affective and sensor-motor skills and positively influence the motivation of users, in relation to interactive educational software.

Auxiliary hypothesis of the research is: the colors and forms of navigation keys affect the user's ability to learn.

\section{Realization of Educational Game Model}

The basic power of HCI approach of designing users' interface is the contact with users. Because of that, a special attention should be paid to specific characteristics of users.

Depending on the system type which is being designed, the focus is put on different characteristics of users. It is impossible to satisfy all users so the target group is defined and attention is concentrated on typical representatives of the group. Relevant factors at categorization of the users' target group:

- the time for studying - how much time a typical member of the group needs in order to learn how to use commands relevant for the task,

- Performance - how much time a typical member of the group needs in order to solve the problem (including mistakes and correction),

- Mistakes - what type of mistakes/errors a typical user makes and how often he/she makes them during solving the problem (error handling),

- The time necessary for repetition - how a typical group member maintains his/her knowledge,

- Satisfaction - how much a typical group member likes different aspects of the software (interviews, surveys of users,...) (Karuovic\&Radosav, 2006).

In the figure 2 the interactive model at creating educational game for preschool children is presented.

Activity diagram of designing the forms of educational games include the following processes:

- selection of processed multimedia material (pictures, text, audio and video),

- designing the menu, 
Karuovic, D.; Radosav, D. \& Glusac, D.: Educational Game Model for Pre-School ...

- design the navigation keys,

- creating a management action,

- networking and facilities management action forms,

- test forms, and correct perceived errors.

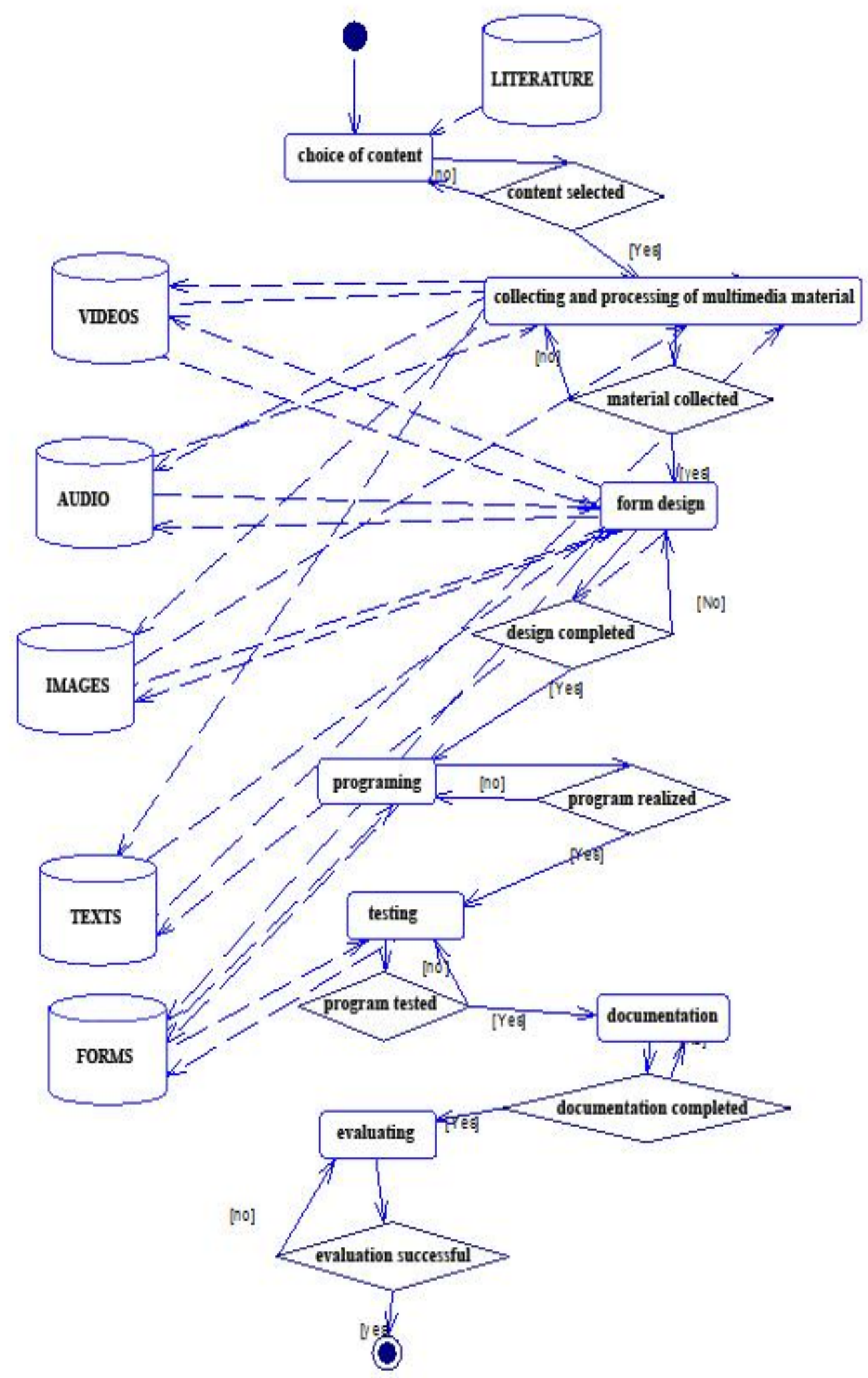

Fig. 2. Business process model of interactive educational game 


\section{Educational game model}

The game "Mathematics" has been developed for the youngest users. Besides having educative character, a very important component of the game is to develope sense-motorical abilities of users. The purpose of the game is to complete the circle. The parts of the circle are very striking, both for color and size. Different sounds are heard during completing the circle if users play correctly or incorrectly. At the start of the game users are given an information containing characteristic sounds for correct and incorrect move. By moving the «mouse» along the circle, a sound is heard which informs users about the part of the circle they are on.

The second part of the software "Mathematics" is related to addition and substraction of numbers. Users are given voice instruction at the beginning. Before every task, a voice explains what is expected from the users to do. By moving the «mouse» along any part of the screen, the voice instruction is heard. Users are enabled to use shortcuts on the keyboard for every action.

\section{Empiric Research}

The region of Vojvodina has 44 preschool institutions in 42 counties and the city of Novi Sad. The program of education work for children between 3 and 7 has been organized in Serbian, Hungarian, Slovakian, Romanian, Russian, Croatian and Gipsy. It is also organized bilingual in multinational communities. The sample for this research was made of 349 interviewees aged 6-7. The information is related to the group of children in Zrenjanin, Novi Sad and Subotica.

The preschool children see learning through the game.The scientific researches have been made in the field of IT experts at The Technical Faculty "Mihajlo Pupin" in Zrenjanin; professor of informatics; the subject name Projecting ES.

During the preliminary research, which included the preschool children from Zrenjanin, the aim was to reveal how the children learn with the help of computers, and the software in the field of mathematics that is created at the Technical Faculty "Mihajlo Pupin" in Zrenjanin was presented to them.

The choice was to use the parallel groups relatively equal. This technique made it possible to compare the results between these two groups (one in a control way of work, and the other in an experimental one). The groups were equal in number, computer literate, age, sex. Defining the computer literacy has been undertaken by testing the skills and afterwards the efficiency of teaching and learning has been also put to the test after the experiment is done. The variables of knowledge and time use the techniques of testing. The instruments used here are tests in software. The procedures taken are documentations analysis, observing and testing. 
Karuovic, D.; Radosav, D. \& Glusac, D.: Educational Game Model for Pre-School ...

\section{Discussion on the results of the research}

In the software »Mathematics « which has been realized for pre-school children, the acceptance of certain colors and forms in educative games has been researched. A number of 349 children was tested. A circle, a triangle and a rectangle were presented. The presented colors were: red, blue, green, yellow, pink, violet, black, brown and white. The background was equal for all. The idea was to determine the color and the shape which should be used, in order to design buttons in games for children if the background contained more than three colors. The results are presented in the Table 1 and they represent average values of access to each object. The task was to click on a certain shape as many times as possible while the software registers the values. The results were obtained on the grounds of all tested children.

\begin{tabular}{|c|c|c|c|c|c|c|c|c|}
\hline \multicolumn{3}{|c|}{ Circle } & \multicolumn{3}{c|}{ Triangles } & \multicolumn{3}{c|}{ Rectangles } \\
\hline Red & Blue & Green & Yellow & Pink & Violet & Black & Brown & White \\
\hline 22.02 & 24.42 & 24.07 & 18.77 & 19.55 & 18.55 & 25.4 & 27.05 & 26.3 \\
\hline
\end{tabular}

Tab. 1. The results of empiric research - buttons

A conclusion can be derived from the presented table that rectangular buttons are the most suitable for children, which is clear taking into account their real surface. Another conclusion is that the children dislike black colour while accessing the rectangles.

The most noticeable color is blue concerning the buttons in the shape of a circle.

Triangles are the most difficult to approach so they should be avoided in designing buttons in educative softwares for pre-school children.

Research has shown that learning by educational games for preschool children affected by the following: reading skills of users (if the questions posed with only text labels but software is designed for the youngest users), ability to understand (if the questions posed by speech, but users are from different cultures), conditions in which the user solve specific tasks (software and hardware computer performance, noise in the classroom, the current concentration) ....

These restrictions, according to the authors, can easily exceed the following: implement software that matches the user's age - do not use text on the screen, if users do not know how to read, create software that will be tailored to the cultural characteristics of users, always make learning conditions in the mouth for all subjects - on the same hardware and software platforms, the same number of respondents, ...

\section{Summary and Implications for Further Research}

The future research should test the effects of using satisfactory factors like colors, animations and sound on potential players. The youngest users have the 
opportunity to examine their ability to use computers while using educational games presented in this paper. Educational games develop imagination and cognitive and psycho-motor capabilities of users.

Since the population of online players, especially the youngest ones, will increase in the following years, the research within the users' acceptance of online computer games and their graphic user interface will become more and more important.

\section{Conclusion}

Studies, like this, are of big help to develop qualitative and more usable games for all age groups so that the computer can be taken as a basic educational tool.

Designing of user interface is a very complicated process, including the appearance of new subjects that need to be observed and of new questions that are to be answered.

It can be concluded that an interactive educational game for the same time provide a more direct knowledge of users, as well as a higher level of development of cognitive, affective and sensor-motor skills and positively influence the motivation of users, in relation to interactive educational software.

Experimental results indicate the need to develop users skills in applying computer to maximize the effects of learning. It was observed that pre-school children more easily and accurately performed set tasks during the implementation of educational games in relation to educational software.

It can be concluded that colors affect the ability to learn.

\section{References}

Ajzen, I., \&Fishbein, M. (1980). Understanding attitudes and predicting social behavior. Englewood Cliffs, NJ: Prentice-Hall.

Chapman, N. \&Chapman, J. (2006). Web design, a complete introduction, John Wiley \& Sons Ltd, England, pp.505,558

Chen, Q. and Wells, W. D. (1999). Attitude Toward the Site", Journal of Advertising Research, vol. 39, no. 5, pp. 27-37.

Davis, F. D., Bagozzi, R. P., \&Warshaw, P. R. (1989). User acceptance of computer technology: A comparison of two theoretical models. Management Science, 35, 982-1003.

Fishbein, M., \&Ajzen, I. (1975). Belief, attitude, intention, and behavior: An introduction to theory and research. Reading, MA: Addison-Wesley

Gao, Y. (2005). Applying the technology acceptance model to educational hypermedia: A field study. Journal of Educational Multimedia and Hypermedia, 14(3), 237-247.

Gilkey R. and Kilts C., November 2007. Cognitive fitness, Harvard Business Review 
Karuovic, D.; Radosav, D. \& Glusac, D.: Educational Game Model for Pre-School ...

Karuovic, D. \&Radosav, D. (2006) User Interface Model of Interactive Education Software, $29^{T H}$ International Convention MIPRO 2006, ISBDN 953-233-021-6 Proceedings Vol.IV

Karuovic, D., Radosav, D. \& Glusac, D. Designing the Interactive Education Software for Preschool Children, $31^{\text {ST }}$ International Convention MIPRO 2008, Opatija, Croatia, Proceedings Vol.IV CE-Computer in Education, 2008, str. 189- 194, ISBN 978-953-233-039-7

Mayo M. J. ,Games for science and engineering education, Communications of the ACM, July 2007/ Vol. 50, No. 7, pp. 30 - 35

Marshall, J. (1998). Creating Electronic Learning Environments: Games, Flow and the User Interface, Proceedings of Selected Research and Development Presentations at the National Convention of the Association for Educational Communications and Technology, St.Louis, 1998

Prensky, M., 2007. Digital Game-Based learning, Paragon House Publishers

Radosav, D. \& Marušić, T. (2007). The design of user interfaces for interactive learning models, Technology, information and education for learning and knowledge society, Beograd, 2007 